Program among oral contraceptive users. ${ }^{11}$ Oral contraceptives can influence various factors concerned in biliary excretion such as hepatic uptake, metabolic conjugation, secretion, and the permeability of the biliary tree, ${ }^{12}$ and it seems likely that such changes may be important in the formation of lithogenic bile.

Both the oestrogen and progestogen components of the pill may be responsible for the cholestasis, ${ }^{2} 713$ and there is also some evidence from clinical studies for a synergistic effect. ${ }^{14}$ Synthetic progestogens such as chlormadinone ${ }^{15}$ and megestrol, ${ }^{14}$ which are derived from hydroxyprogesterone, are not 17- $\alpha$ substituted 19-norsteroids and do not produce jaundice. However, chlormadinone has been removed from the market because it produces breast tumours in dogs, and megestrol is used in only a few preparations. Oral contraceptive preparations containing only a low dose of progestogen (usually norethisterone) which are taken continually have recently been introduced and are still under evaluation. ${ }^{16}$

Three other possible rare hepatic complications of the use of oral contraceptives should be mentioned. Firstly, an increased incidence of neonatal jaundice has been reported in babies born to mothers who used oral contraceptives, though a more recent survey has failed to confirm this association. ${ }^{17}$ Secondly, a small number of cases, most often fatal, of thrombosis of the hepatic veins (Budd-Chiari syndrome) has been noted in young women on the pill. ${ }^{18}$ Finally, oral contraceptives are a possible cause of benign hepatic adenomata; this was discussed in an earlier leading article. ${ }^{19}$

What are the contraindications for oral contraceptive therapy in patients with a history of liver disease ? There seems to be no reason to withhold them in women with a history of viral hepatitis if the liver function tests have returned completely to normal. In women who have a history of pruritus or cholestatic jaundice of pregnancy or benign familial recurrent cholestasis there is a greater chance that cholestasis will develop during oral contraceptive therapy, ${ }^{4}$ but this is by no means invariable, and the risk may have been exaggerated. ${ }^{20}$ In this group of patients and those who have had one attack of cholestasis due to oral contraceptive therapy one of the new progestogen preparations may deserve a trial. In patients with pre-existing chronic liver disease, especially active chronic hepatitis and primary biliary cirrhosis, as well as in the Dubin-Johnson syndrome (a form of congenital hyperbilirubinaemia) oral contraceptive therapy may lead to a deterioration in liver function, ${ }^{4}$ and in these conditions other forms of contraception are to be preferred.

1 Lancet, 1974, 1, 1147.

2 Adlercreutz, H., and Tenhunen, R., American fournal of Medicine, 1970,

3 Ockner, R. K., and Davidson, C. S., New England fournal of Medicine, 1967, 276, 331 .

1967, 276, 331. Mowat, A. P., and Arias, I. M., fournal of Reproductive Medicine, 1969,
4.

3, 19.

- Stoll, B. A., Andrews, J. T., and Motteram, R., British Medical fournal, $1966,1,960$.

7 Drill, V. A., American fournal of Obstetrics and Gynecology, 1974, 119, 165.

8 Drill, V. A., American fournal of Obstetrics and Gynecology, 1974, 119, 165.

9 Somayaji, B. N., et al., British Medical Fournal, 1968, 2, 281.

10 Dalén, E., and Westerholm, B., Acta Medica Scandinavica, 1974, 195, 459.

11 Lancet, 1973, 1, 1399.

12 Smith, R. L., Acta Endocrinologica, 1974, suppl. no. 185, p. 149.

3 Urban, E., Frank, B. W., and Kern, F. jnr., Annals of Internal Medicine, $1968,68,598$.

14 Eisalo, A., Heino, A., and Räsänen, V., Acta Obstetrica et Gynaecologica Scandinavica, 1968, 47, 58.

15 Thompson, R. P. H., and Williams, R., British Medical fournal, 1970,

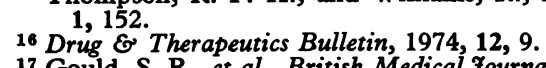

17 Gould, S. R., et al., British Medical fournal, 1974, 3, 228.

18 Hoyumpa, A. M. jun., Schiff, L., and Helfman, E. L., American fournal of Medicine, 1971, 50, 137.

19 British Medical fournal, 1974, 3, 3.

20 Rannevik, G., Jeppsson, S., and Vivllander, S., Fournal of Obstetrics and Gynaecology of the British Commonwealth, 1972, 79, 1128.

\section{Daunorubicin and the Heart}

Daunorubicin (rubidomycin) and the closely related adriamycin are antibiotics with a powerful cytotoxic action which is particularly effective in acute myeloblastic leukaemia but is useful also in a number of other leukaemias and sarcomas. The onset of cardiac failure in patients given daunorubicin has been recognized as a hazard of the drug ever since its introduction, but the picture has not been clear since many of the patients developing heart failure had also had advanced, uncontrolled sarcoma or leukaemia in relapse.

In a recent randomized controlled trial ${ }^{1}$ of treatment of childhood acute lymphocytic leukaemia the cardiac toxicity of daunorubicin was shown particularly clearly. Heart failure developed in 17 out of $172(9.9 \%)$ of the children, all of whom were in complete remission at the onset of cardiac symptoms. Six of the children treated with daunorubicin died from heart failure; none of those who had not received the drug showed any evidence of heart disease. In this series the mean dose of daunorubicin in the 17 children with signs of cardiac toxicity was $780 \mathrm{mg} / \mathrm{m}^{2}$ and ranged between 360 and $1260 \mathrm{mg} / \mathrm{m}^{2}$.

This and other studies ${ }^{2-6}$ have shown that the cardiac toxicity is dose-dependent in children, but in adults toxicity is less predictable and may develop abruptly despite low dosage. This greater susceptibility of older hearts is also well documented and heart failure in the elderly has been reported" 7-9 even in "safe" doses of only $55-200 \mathrm{mg} / \mathrm{m}^{2}$.

The importance of the interval between doses and the total duration of treatment in relation to the development of cardiac toxicity is still not clear. After an induction dose, maintenance treatment is usually given monthly. The onset of cardiac symptoms does not usually occur for between three and six months after starting treatment but may be delayed for weeks or even months after its end. In Halazun's study ${ }^{1}$ the time interval from the first dose of daunorubicin to the onset of cardiac toxicity ranged from 105 to 1,348 days and the time intervals from the last dose to the onset of signs of cardiac toxicity ranged between 18 and 280 days but was usually less than 100 days. Transient cardiac symptoms or abnormal signs during or after administration of the drug have not been reported but should be sought.

Heart failure induced by daunorubicin develops remarkably suddenly with sinus tachycardia, hypotension, dyspnoea, tachypnoea, and gallop rhythm, but no oedema at this stage. The chest radiograph may show little cardiac enlargement but there is usually some evidence of pulmonary venous congestion. Death may be swift. Patients who survive longer may develop cardiac dilatation and fluid retention; the initial response to diuretics is good, but deterioration usually follows. Early electrocardiographic changes are slight and easily missed: there is a fall in voltage followed by changes in the QRS and ST segments and T waves indicating abnormality in the depolarization and repolarization forces. With continuing heart failure changes occur in the $P$ waves due to left atrial or biatrial dilatation, but signs of ventricular hypertrophy or infarct-like patterns are absent, probably because the patients do not survive long once cardiac failure has developed.

Detailed studies of cardiac function have been very limited, but in Halazun's series systolic time intervals had been measured showing changes attributable to diminishing myocardial contractile efficiency with slowed velocity of contraction and diminishing stroke volume. At necropsy the hearts usually showed some generalized dilatation, but even this may be absent when death comes rapidly after the onset of cardiac failure. Ventricular mural thrombosis is sometimes seen and 
may lead to embolism in life. Buja and Ferrans ${ }^{10}$ have described the ultrastructural changes in these hearts, which show degenerating and atrophic myocardial cells with alterations of nuclear chromatin and changes in the mitochondria. Cardiac failure from daunorubicin has been produced in animal experiments; again the effect has been dose-related. ${ }^{11-13}$

The mechanism of daunorubicin cardiac toxicity is not completely known but is thought to be related to binding of the drug to DNA in nuclei and mitochondria. The bound drug is only very slowly excreted from the cell, and since the cardiac muscle cell cannot reproduce itself any inhibition of protein synthesis resulting from drug-induced alteration in the DNA templates might be long lasting. Cumulative interference with the processes of normal protein regeneration, replenishment, and growth could explain the delayed onset of toxicity-and also the observation that adults are more vulnerable than children and the elderly most susceptible of all.

Since the first introduction of daunorubicin other drugs have appeared. Nowadays multiple drug schedules are used, doses of daunorubicin are spaced at wider intervals, and the total dose given can be less. Daunorubicin is less often used in the treatment of acute lymphoblastic leukaemia in children but remains one of the best drugs for the treatment of acute myeloblastic leukaemia. It may be that adriamycin, which has twice the antileukaemic potency of daunorubicin, may have no more cardiac toxicity dose for dose so that cardiac toxicity would be less likely. Meanwhile precautions which should further reduce the incidence of cardiac toxicity would be limitation of the total dose of daunorubicin to not more than $500 \mathrm{mg} / \mathrm{m}^{2}$ in children or $200 \mathrm{mg} / \mathrm{m}^{2}$ in adults, wider spacings between individual treatments, and careful cardiac monitoring. The most sensitive tests of cardiac function which are noninvasive and therefore repeatable are probably the measurement of the systolic time intervals of the left ventricle and ultrasonic recording of the movements of the left ventricular wall. Recognizable changes in the nuclei and mitochondria of the myocardial cell have been reported after administration of fatal doses of daunorubicin, so catheter biopsy of the septal wall of the right ventricle using the Japanese technique may possibly provide the most sensitive indication of impending cardiac damage.

Cardiac damage resulting from daunorubicin and adriamycin appears, therefore, to result from a primary toxicity which is not secondary either to the leukaemic process or to damage to other organs, and while these drugs retain their place in the control and possible cure of an otherwise fatal disease steps must be taken to prevent or minimize cardiac damage. It is probably possible to achieve this without vitiating their antileukaemic efficacy.

\footnotetext{
1 Halazun, J., Wagner, H. R., Gatfa, J. F., and Sinks, L. F., Cancer, 1974, 33, 545.

2 Bernard, J., et al., Presse Médicale, 1967, 75, 951

3 Jones, B., et al., Cancer Research, 1971, 31, 84. Shore, N. A., Proceedings of the American Association for Cancer Research, $1969,10,80$.

5 Holton, C. P., et al., Cancer, 1968, 22, 1014.

- Romano, C., et al., Minerva Pediatrica, 1970, 22, 71.

7 Marmont, A. M., Damasio, E., and Rossi, F., Lancet, 1969, 1, 838.

8 Bonadonna, G., and Monfardini, S., Lancet, 1969, 1, 837.

- Malpas, J. S., and Scott, R. B., Lancet, 1969, 1, 469.

10 Buja, L. M., et al., Cancer, 1973, 32, 771.

11 Ainger, L. E., et al., fournal of the National Medical Association, 1971, $63,261$.

12 Maral, R., et al., Pathologie et Biologie, 1967, 15, 903.

13 Farmar, R. M., Proceedings of the American Association for Cancer Research, $1969,10,23$.
}

\section{Lord Halsbury Departs}

Last week Lord Halsbury finally resigned from the chair of the Review Body (p. 479). Few will doubt that this was the right step, for if the pay review machinery is to work the professions must have complete confidence in its independence. Lord Halsbury's reported interview in Pulse and its sequelae had cast a shadow on that independence. ${ }^{1}$

Chairing the Review Body is no sinecure. Lord Kindersley and his colleagues had had their ups and downs with the profession but their collective resignation in 1970 was because they saw their independence ${ }^{2}$ directly challenged by the Government. Taking over in such circumstances Lord Halsbury was very much on test and his term of office has been overshadowed by a statutory incomes policy. Doctors' irritation over the restraints on their pay has inevitably rubbed off on the Review Body and there have been growing doubts about the practicability of such a system in the 1970 s when confrontation has proved such an effective trade union weapon.

When the Pilkington Royal Commission proposed the Review Body machinery in 1960 statutory control over pay seemed unlikely. But its members were farsighted enough, however, to draw up broad terms of reference and in declining "to define exactly" the factors which the Review Body should consider stated also: "It would be presumptuous on our part, after recommending the appointment of persons of eminence and authority, to seek to tie their hands for years ahead in circumstances of which we are not at present aware." Furthermore, the Royal Commission emphasized the importance it attached to the aim "of giving the medical and dental professions confidence that their remuneration would not be determined by considerations of political convenience." It was the uneasy feeling among doctors that this was just what Lord Halsbury seemed not to be doing that undermined the profession's confidence in him.

So far as doctors and dentists were concerned the disagreement lay between them and Lord Halsbury himself. Thus the B.M.A.'s joint evidence committee acceded promptly to the request from other Review Body members for a "vote of confidence" from the profession in their independence. Some doctors may even have reservations about this but on balance there is little doubt that an independent Review Body is still an asset to the profession, as those who have experience of negotiating under the previous system will confirm. The system deserves a chance to prove its effectiveness in postphase 3 conditions.

In fact that chance should be soon. It is three months since the B.M.A. submitted evidence for an interim review, based largely on the Review Body's own figures of the relative deterioration of doctors' incomes. ${ }^{3}$ Apart from the inroads of inflation upon all doctors' pay general practitioners are worried about the mounting costs of running their practicesoverdrafts are expensive in 1974. While the Review Body may reasonably plead that some delay is attributable to Lord Halsbury's difficulties the evidence given to it was straightforward. So what is there to prevent a report, perhaps signed by an acting chairman, being in the Prime Minister's hands very soon?

\footnotetext{
1 British Medical fournal, 1974, 4, 119.
2 British Medical fournal, 1970, 2, 615.

3 Review Body on Doctors' and Dentists' Remuneration, Fourth Report 1974, Cmnd. 56440. London, H.M.S.O., 1974.
} 